\title{
Taxa de variação da linha de costa e faixas de proteção nas áreas contíguas à desembocadura do rio Sergipe, Aracaju, Sergipe
}

\author{
Luciana V. JESUS \& Ana Cláudia S. ANDRADE
}

Laboratório de Geologia Costeira e Ambiental, Programa de Pós-Graduação em Geociências e Análise de Bacias, Universidade Federal de Sergipe. Cidade Univ. Prof. José Aloísio de Campos, Av. Marechal Rondon, s/n, Jd. Rosa Elze, São Cristóvão, CEP 49.100-000, Sergipe, SE, Brasil, CEP 49100-000 (luvieira.geo@gmail.com, acsaa.ufs@gmail.com).

Jesus, L.V. \& Andrade, A.C.S. 2018. Taxa de variação da linha de costa e faixas de proteção nas áreas contíguas à desembocadura do rio Sergipe, Aracaju, Sergipe..Pesquisas em Geociências, 45: e0720.

DOI: https://doi.org/10.22456/1807-9806.91389

Resumo. As praias dos Artistas e da Atalaia (porção norte), localizadas em Aracaju, Sergipe, estão sujeitas à atuação dos agentes costeiros (ondas, correntes e ventos) e da dinâmica da desembocadura do rio Sergipe. Nessas praias, no período de 2007 a 2008, ocorreram eventos erosivos severos que acarretaram na destruição de diversas estruturas antrópicas (praça de eventos, bares/restaurantes, etc.). Este trabalho teve como objetivo calcular a taxa de variação da linha de costa e a largura da faixa de proteção na área contígua à desembocadura do rio Sergipe após severa erosão ao sul. A metodologia consistiu em: (i) análise multitemporal (2008 a 2015) da linha de costa utilizando imagens de satélite e perfis de praia; (ii) cálculo da taxa de variação da linha de costa pelo método End Point Rate (EPR); (iii) determinação da largura de faixa de proteção. As taxas de recuo da linha de costa na área investigada, que variaram de -0,5 a $-13 \mathrm{~m} / \mathrm{ano}$, permitiram sugerir o estabelecimento de duas faixas de proteção: $360 \mathrm{~m}$ para construções leves e $730 \mathrm{~m}$ para construções pesadas, respectivamente. As praias estudadas possuem estrutura de contenção à erosão, que não recebem manutenção sistematicamente. 0 problema de erosão em alguns pontos da área investigada não foi solucionado definitivamente devido à reincidência de eventos erosivos. Dessa forma, medidas preventivas, a exemplo da utilização de faixas de proteção recomendadas nesse trabalho devem ser incentivadas. Palavras-chave. análise multitemporal, erosão, taxa de recuo, medidas preventivas.

Palavras-chave. análise multitemporal, erosão, taxa de recuo, medidas preventivas.

\begin{abstract}
SHORELINE RATE-OF-CHANGE AND SETBACK LINE ON ADJACENT AREAS OF SERGIPE RIVER'S mouth, Aracaju, SergiPe. The "Artistas" and "Atalaia" beaches, located in Aracaju, Sergipe, are subject to coastal processes (waves, currents and winds) and to Sergipe's river mouth dynamics. From 2007 to 2008, severe erosive events, that led to the destruction of anthropogenic structures (events plaza, bars/restaurants, etc.), occurred on these beaches. This work aims to calculate the shoreline rate-of-change and the setback lines nearby Sergipe's river mouth. The methodology consisted of: (i) historical analysis of shoreline positions using data from satellite images and beach profiles (from 2008 to 2015); (ii) calculation of the shoreline rate-of-change using the End Point Rate (EPR) statistics method; and (iii) determination of setback lines. Shoreline retreat rates in the investigated area, which ranged from -0.5 to $-13 \mathrm{~m} / \mathrm{yr}$, allowed the establishment of two setback lines: $360 \mathrm{~m}$ for soft constructions and $730 \mathrm{~m}$ for hard constructions, respectively. The studied beaches present erosion protection structures, but they do not receive maintenance systematically. The erosion problem at some points was not solved definitively due to the recidivism of erosive events. Therefore, preventive measures, such as the use of setback lines recommended in this work, should be encouraged. Keywords. historical analysis, erosion, retreat rate, preventive measures.
\end{abstract}




\section{Introdução}

A linha de costa é definida como a interface entre o continente e o oceano, e sua posição varia em função da intensidade dos agentes costeiros, tais como ondas, marés e correntes costeiras (Boak \& Turner, 2005; Bird, 2008). A posição da linha de costa é afetada pelos processos de erosão, transporte e deposição de sedimentos (Forbes \& Liverman, 1996). As variações na configuração da linha de costa podem ou não estar relacionadas com as variações nos perfis topográficos das praias. Quando prevalece a erosão nos perfis, a linha de costa pode recuar no sentido do continente. Quando prevalece a deposição, a linha de costa pode a avançar no sentido do oceano (Bird, 2008).

As mudanças na posição da linha de costa são mensuradas usando uma variedade de técnicas (Smith \& Zarillo, 1990), que podem ser tratadas de forma isolada ou associadas entre si (Moore, 2000). As fontes de dados mais comuns incluem: fotografias aéreas, mapas, cartas náuticas e perfis de praia (Dolan et al., 1991). Os estudos de longo e médio prazo, em geral, utilizam mapas, cartas náuticas, fotografias aéreas e/ou imagens de satélite (Morton, 1996) e os de curto prazo utilizam perfis de praia (Smith \& Zarillo, 1990). Para Crowell et al. (1991, 1993) e Stive et al. (2002), as mudanças de longo prazo são aquelas que ocorrem em um período de tempo maior que 60 anos, as de médio prazo são aquelas que ocorrem em períodos de 10 a 60 anos e as de curto prazo ocorrem em intervalos de tempo inferiores a 10 anos.

As vantagens da utilização de perfis de praia para monitoramento da linha de costa incluem: (i) diminuição da incerteza quanto à identificação da linha de costa, e (ii) movimentação da linha de costa baseada em dados reais medidos em campo e não interpretados indiretamente a partir de imagens aéreas (Morton, 1996).

Para uma análise consistente das variações da linha de costa são necessários dados anuais ou mais frequentes. Se a finalidade for entender os processos de erosão e transporte de sedimentos, observações de eventos de tempestades ou eventos meteorológicos devem ser consideradas (Forbes \& Liverman, 1996).

A taxa de variação da linha de costa é uma das medidas mais comuns utilizadas por cientistas costeiros para indicar a dinâmica e os riscos costeiros (Dolan et al., 1991). Métodos simples de medições dessas taxas, tais como EPR (End Point Rate) e regressão linear têm sido propostos na literatura e são amplamente utilizados (Dolan et al., 1991; Douglas \& Crowell, 2000; Honeycutt et al., 2001; Genz et al., 2007; Esteves et al., 2009; Mazzer \& Dillenburg, 2009; Souza \& Luna, 2010). 0 método EPR tem a vantagem de utilizar apenas dois valores de linha de costa, no entanto, esse fato suprime os valores intermediários, perdendo-se, assim, as mudanças ocorridas nesse período (Dolan et al., 1991). Foster \& Savage (1989) salientam que o método da Regressão Linear apresenta a melhor estimativa para quantificar as variações da linha de costa. Por outro lado, segundo Ferreira et al. (2006), o método EPR pode ser utilizado em estudos que apresentam baixa disponibilidade de dados multitemporais.

As taxas de variação negativas indicam recuo da linha de costa. Quando isso ocorre é necessário utilizar medidas corretivas ou preventivas, das quais se destacam, nesse último caso, as faixas de proteção (setbacks lines) (Muehe, 2001). As faixas de proteção consistem em regiões de proibição ou restrição de todos ou alguns tipos de uso e ocupação antrópica. Essas faixas são adotadas para manter as características paisagísticas e prevenir perdas materiais em decorrência da erosão costeira. As taxas de recuo da linha de costa são utilizadas para o estabelecimento dessas faixas de proteção (Muehe, 2004). Como a região costeira está em constante mudança, é importante considerar um período de tempo associado a uma determinada proposta de largura de faixa de proteção. Uma abordagem razoável é a de considerar um período de 50 anos para empreendimentos habitacionais (DEA\&DP, 2010). Dessa forma, a faixa de proteção deve ser sempre modificada a partir da aquisição de novos dados de pesquisas geológicas, geomorfológicas e oceanográficas (Muehe, 2004).

No Brasil, o Decreto de Lei 9.760, de 05.09.1946, art. $2^{\circ}$ estabelece uma faixa non-aedificandi de $33 \mathrm{~m}$ medidos a partir da preamar de sizígia (Freitas, 2011). No entanto, esse limite não considera a dinâmica do ambiente e em muitas regiões não ultrapassa a largura do pós-praia, prin- 
cipalmente em praias largas e com características morfodinâmicas dissipativas (Muehe, 2004).

Segundo Terich (1987), o estabelecimento de faixas de proteção incluem: (i) vantagens: reduz a ameaça de destruição das edificações na retaguarda da praia, permite que os processos costeiros operem sem interferência, preserva os valores recreativos e estéticos da praia, não há custos de manutenção a longo prazo e não existem problemas de licenciamento de novos imóveis; e (ii) desvantagens: não interrompe a erosão costeira e pode reduzir a vista para o mar.

As linhas de costa do Brasil e do mundo encontram-se em constante modificação (Bird 2008). O litoral de Sergipe não foge à regra e apresenta cenários de erosão costeira severa reportados por Oliveira (2003), Bittencourt et al. (2006), Andrade et al. (2010), Jesus et al. (2014), Silva (2014) e Rodrigues et al. (2015a). 0 processo erosivo no estado é comum e conta, ainda, com um fator agravante que é o fato de tratar-se de uma costa arenosa de baixa altitude, ou seja, de fácil erosão e inundação.

Com as previsões de subida do nível do mar e intensificação da ação de ondas de tempestades (IPCC, 2007) torna-se necessário o estabelecimento de medidas preventivas. Rodrigues (2008) sugere uma faixa de proteção mínima de $500 \mathrm{~m}$ para as áreas contíguas à margem direita da desembocadura do rio Sergipe (Aracaju). Esse valor é baseado nas variações ocorridas (cerca de 210 m) na linha de costa em um período de aproximadamente 50 anos. No entanto, a autora não utiliza taxas de recuo de linha de costa para estipular esse valor, e também não mostra como foi determinada a largura dessa faixa.

Dentro desse contexto, este trabalho visa sugerir faixas de proteção nas vizinhanças da margem direita da desembocadura do rio Sergipe (praia dos Artistas e porção norte da praia de Atalaia), município de Aracaju, Sergipe.

\section{2 Área, materiais e métodos}

\subsection{Caracterização regional}

O litoral do município de Aracaju, Sergipe, apresenta-se em planta na forma de arco que se estende por cerca de $24 \mathrm{~km}$ e compreende as praias do Mosqueiro, Náufragos, Refúgio, Robalo, Aruana, Atalaia e Artistas. É limitado a sul e a norte pelas desembocaduras dos rios Vaza-Barris e Sergipe (Fig. 1). A linha de costa do município, que apresenta orientação predominante NE-SW, é bordejada por terraços marinhos holocênicos, manguezais e dunas (Bittencourt et al., 1983).

0 clima do litoral de Aracaju é quente e úmido, com temperatura média anual de $27^{\circ} \mathrm{C}$. Há duas estações bem definidas: período seco, que ocorre nos meses mais quentes (novembro a fevereiro), e período chuvoso que ocorre durante os meses com temperaturas mais amenas (maio a agosto). A precipitação pluviométrica é geralmente inferior a $30 \mathrm{~mm}$ nos meses mais quentes e superior a $100 \mathrm{~mm}$ nos meses com temperaturas mais amenas (INMET, 2011). A precipitação média total é de cerca de $1.600 \mathrm{~mm}$ /ano (SRH, 2011). Os ventos predominantes no litoral de Aracaju são advindos do quadrante leste (NE, E e SE) (INMET, 2011). 0 rio Sergipe apresenta vazão média anual de 13,84 $\mathrm{m}^{3} / \mathrm{s}$ (ANA, 2000).

As marés são do tipo meso-marés, semidiurnas, com altura máxima de 2,3 m e mínima de $-0,1 \mathrm{~m}$ na maré de sizígia e altura máxima de $1,9 \mathrm{~m}$ e mínima de 0,5 m na maré de quadratura (DHN, 2016). As ondas que chegam ao litoral de Sergipe possuem direções predominantes de E, NE, SE e N e alturas que variam de 1 a $3 \mathrm{~m}$, a depender da estação do ano. No verão, as ondas predominantes são advindas de E com alturas de 1 a 2 m e períodos de 6 a 8 s. No inverno, as direções predominantes são SE e E com alturas de 1 a 3 m e períodos de 6 a 10 s (Pianca et al., 2010). 0 sentido da corrente longitudinal de sedimentos no litoral do estado é predominantemente de NE para SW (Oliveira, 2003). Entretanto, ocorre localmente inversão no sentido do transporte, de NE-SW para SW-NE, nas praias dos Artistas e da Atalaia (Rodrigues, 2014).

\section{2 Área de estudo}

A área de estudo desse trabalho, situada na margem direita da desembocadura do rio Sergipe, no município de Aracaju, Sergipe, compreende as praias dos Artistas e da Atalaia (coordenadas UTM: 715125 E e 8786266 N), e apresenta cerca de 1,5 km de extensão (Fig. 1). 


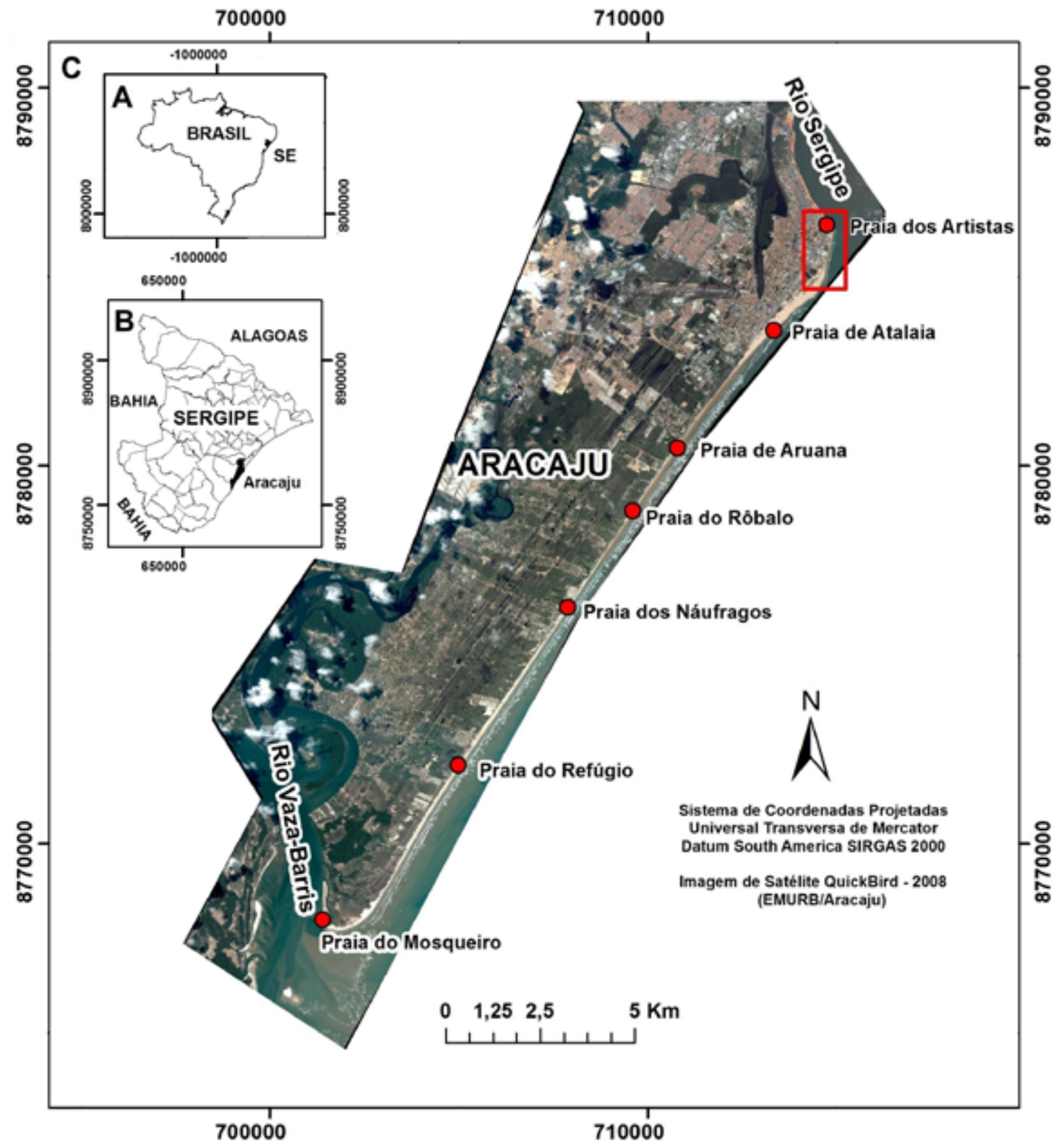

Figura 1. Área de estudo. A) Localização do estado de Sergipe no Brasil; B) Delimitação do município de Aracaju, situada no estado de Sergipe; C) Litoral de Aracaju e localização da área de estudo, na área contígua à desembocadura do rio Sergipe (quadrado vermelho).

Figure 1. Study area. A) Location of the state of Sergipe in Brazil; B) Delimitaion of Aracaju's city placed on the state of Sergipe; C) Location of Aracaju's littoral and location of the study area at adjacent area of Sergipe's river mouth (red square).

A evolução da linha de costa da praia dos Artistas e da Atalaia é marcada por uma expressiva progradação a partir de 1965 (Oliveira, 2003; Rodrigues et al., 2015a). A linha de costa da praia dos Artistas, por alternar períodos de avanço e recuo, é considerada como de elevada variabilidade por Oliveira (2003), Bittencourt et al. (2006) e Rodrigues et al. (2015b). 0 monitoramento da linha de costa através de perfis de praia realizado por Oliveira et al. (2010) e Jesus et al. (2014) corrobora os trabalhos supracitados que utilizam mapas multitemporais em suas análises.
Eventos erosivos ocorridos na área anteriores a 1990 estão associados à migração do canal do rio Sergipe para sul (Oliveira, 2003) e à dinâmica do delta de maré vazante (Oliveira, 2003; Rodrigues et al., 2015b). Segundo Rodrigues et al. (2015b), ocorre passagem (bypass) de sedimentos, no sentido do transporte longitudinal predominante (NE-SW), devido à presença de acumulação de sedimentos na foz do rio Sergipe semelhante aos deltas de maré vazante (ebb tidal deltas).

Em razão da erosão costeira, entre os anos de 1990 e 2000, estruturas de contenção à erosão 
foram instaladas nas margens do rio Sergipe para fixá-las (Wanderley, 2006). As praias da Atalaia Nova (Barra dos Coqueiros) e dos Artistas (Aracaju) foram contempladas com essas obras (Fig. 2). Recentemente, em 2007 e 2008 (Vieira, 2008) e em 2012 e 2013 (Jesus et al., 2014) ocorreram novos eventos erosivos nas praias dos Artistas e da Atalaia.

A retaguarda da área de estudo encontra-se ocupada com estruturas antrópicas construídas próximas à linha de costa: Orla de Atalaia (bares, pista de aeromodelismo, pista de skate, lagos, oceanário), edificações, etc. Nos últimos 5 anos, devido à especulação imobiliária, essa ocupação foi intensificada e verticalizada. A prefeitura de Aracaju apresentou um projeto de revitalização da Orla de Atalaia (Construção da Arena Multiuso na Orla de Atalaia - Aracaju/SE, revitalização da 1a Etapa da Orla da Coroa do Meio - Aracaju/SE - Edital CP 12/2014), anunciado no início do ano de 2014 (MTur, 2013). Essas obras foram planejadas mesmo após a região ter sido alvo de eventos erosivos severos nos anos de 2007-2008 e 20122013. Dessa forma, sem levar em consideração a dinâmica da praia e da linha de costa da área. Por motivos ainda desconhecidos, o canteiro de obras montado em 2015 foi desativado em 2017.

\subsection{Materiais e métodos}

Nesse trabalho foram seguidas as seguintes etapas: (a) levantamento de 6 perfis transversais às praias dos Artistas e da Atalaia (Fig. 3) durante a maré baixa de sizígia utilizando o método das

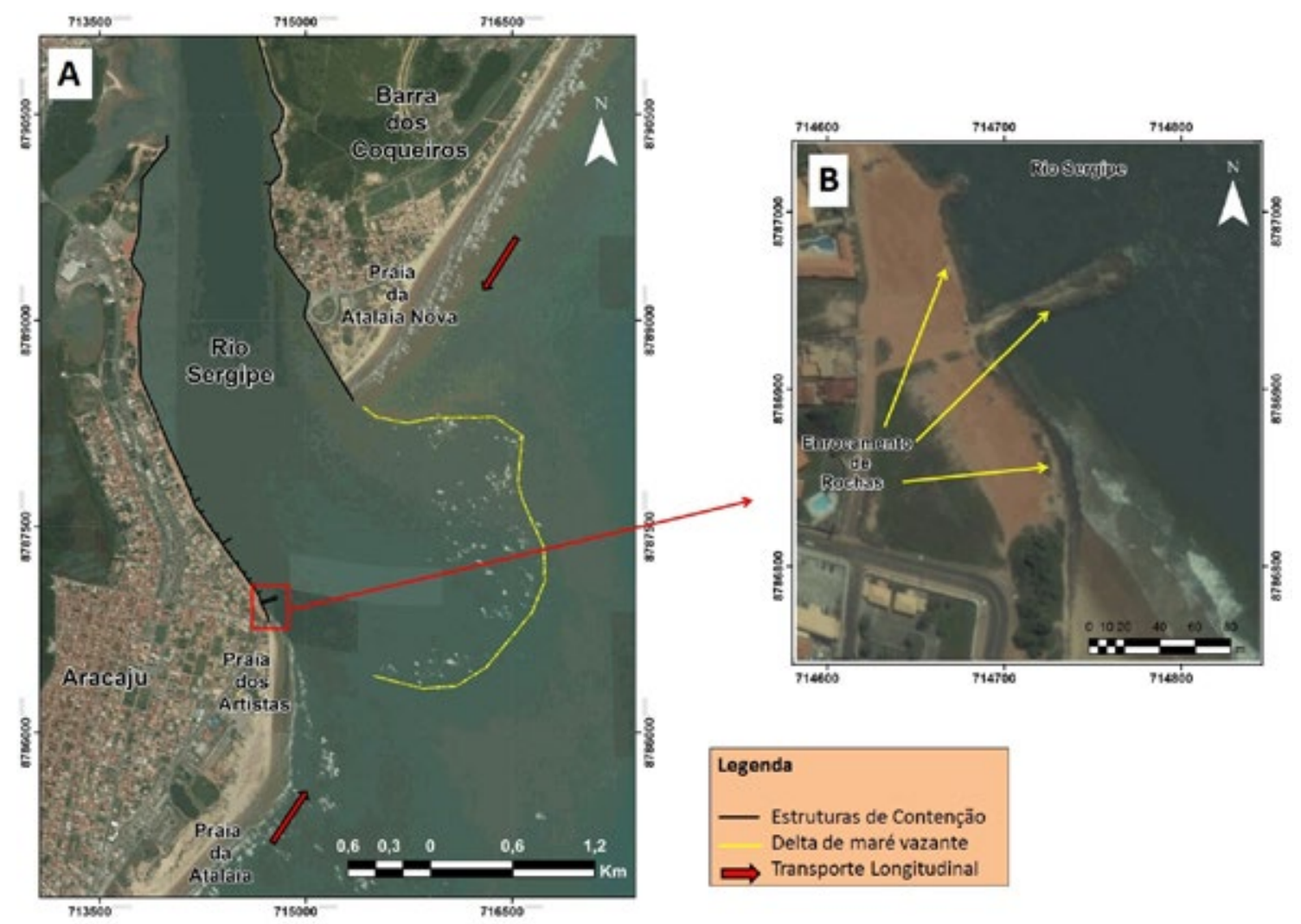

Figura 2. Imagem de satélite do Google Earth Pro de 2015 mostrando a desembocadura do rio Sergipe, Aracaju, Sergipe. A) Imagem de satélite do Google Earth Pro de 2015 destacando as estruturas de proteção e o delta de maré vazante; B) Detalhe da imagem de satélite do Google Earth Pro de 2015 mostrando o enrocamento de rochas na praia dos Artistas. 0 transporte longitudinal mostrado na imagem foi extraído de Oliveira (2003) e Rodrigues (2014). As setas em amarelo indicam a obra de contenção à erosão construída na praia.

Figure 2. Satellite image from Google Earth Pro of the Sergipe's river mouth in 2015. A) Detail of satellite image showing the protection structures and the ebb tidal delta at Sergipe's river mouth; B) Detail of satellite image showing the rip-rap structures at Artistas beach. The longshore current showed at the image was obtained from Oliveira (2003) and Rodrigues (2014). The yellow arrows indicate the rip rap built at the beach. 
balizas de Emery (1961); (b) mapeamento e sobreposição do posicionamento da linha de costa no programa ArcGis 9.3.1® no datum SIRGAS 2000 a partir de dados dos perfis de praia e de imagens de satélite de 03/12/2009, 29/01/2010, 26/09/2011, 25/02/2013 e 22/04/2015 extraídas do Google Earth Pro; (c) cálculo da taxa de variação da linha de costa pelo método EPR e; (d) sugestão de estabelecimento de faixas de proteção para a área de estudo.

Para os perfis de praia 1 e 2, os períodos de análise compreenderam: outubro de 2008 a janeiro de 2013 e outubro de 2008 a fevereiro de 2014, respectivamente. Para os demais perfis, o período de análise foi de outubro de 2008 a julho de 2015. Isso ocorreu, pois no perfil 1, a praia desapareceu entre o levantamento de janeiro e agosto de 2013 e no perfil 2, o ponto de referência foi erodido entre os levantamentos de fevereiro e outubro de 2014. Foram realizados levantamentos quinzenais no período de 2008 a 2009, mensais no período de 2009 a 2010 e sazonais no período subsequente (2010 a 2015). Para a escolha dos dias e horários para realização dos levantamentos, não foi levado em consideração a ocorrência de eventos meteorológicos extremos (e.g. eventos de tempestade).

0 indicador utilizado para efetuar a análise da variação da linha de costa foi a linha de preamar máxima (high tide shoreline de Bird, 2008). De acordo com Crowell et al. (1991), Leatherman (2003) e Esteves et al. (2006), essa linha é um bom indicador de linha de costa pois representa a posição de máximo alcance das ondas durante o dia da obtenção do dado. Adicionalmente, a linha de preamar máxima apresenta continuidade ao longo da área a ser mapeada, e é de fácil identificação e consistência ao ser monitorada através de diferentes fontes de dados. Sendo assim, a distância horizontal entre a linha de preamar máxima e o ponto de referência dos perfis foi medida em cada campanha de campo, tanto nos dados de perfis quanto nas imagens de satélite.

A taxa de variação da linha de costa foi calculada pelo método EPR (End Point Rate ou Taxa de Variação do Ponto de Terminação), descrito por Dolan et al. (1991), a partir dos dados de perfis de praia e de imagens de satélite. 0 cálculo consistiu em dividir a distância total entre a posição de duas linhas de costa de diferentes datas pelo intervalo de tempo decorrido entre as medições (Dolan et al., 1991). A taxa, expressa em metros por ano (m/ano), e os valores positivos (+) e negativos (-) indicaram o deslocamento da linha de costa no sentido do oceano e do continente, respectivamente.

Neste trabalho foi adotado o modelo de estabelecimento de faixas de proteção proposto para as praias da Carolina do Norte (EUA) e mostrado no Projeto Orla (Muehe, 2004), no qual considera as taxas de recuo da linha de costa. Para construções leves (barracas de praia, bares, etc), a largura da faixa de proteção foi de 30 vezes a taxa de recuo (m/ano) e para as construções pesadas (edificações como moradias, hotéis, etc), de 60 vezes o valor da taxa de recuo medidas a partir da linha de vegetação permanente, base da duna, estrutura antrópica, etc. Entretanto, no caso de valores inferiores a largura de uma duna frontal, por exemplo, esse valor foi estendido até o limite ou crista dessa duna para que esta feição fosse protegida (Cicin-Sain \& Knecht, 1998).

\section{Resultados e discussões}

3.1 Taxa de variação da linha de costa obtida pela análise multitemporal de imagens de satélite para o período de 2009-2015

No período de 2009 a 2011, a linha de costa recuou de 40 a 100 m na área investigada, à exceção do perfil 5, que praticamente permaneceu estável. Entre 2011 e 2013, predominou a estabilidade da linha de costa, à exceção do perfil 1 , que recuou, e do perfil 6 que avançou no sentido do oceano. No período de 2013 a 2017, a linha de costa avançou cerca de 25 a $90 \mathrm{~m}$, à exceção do perfil 1. Dessa forma, apenas o perfil 1 apresentou recuo em todo o período investigado, enquanto que a linha de costa nos demais perfis apresentou comportamento bastante variável, ora recuando, ora avançando ou mesmo mantendo-se praticamente estável (Fig. 4).

A taxa de variação da linha de costa no período investigado foi negativa nos perfis $1,2,3$ e 6 , positiva no perfil 5 e nula no perfil 4 (Tab. 1). 


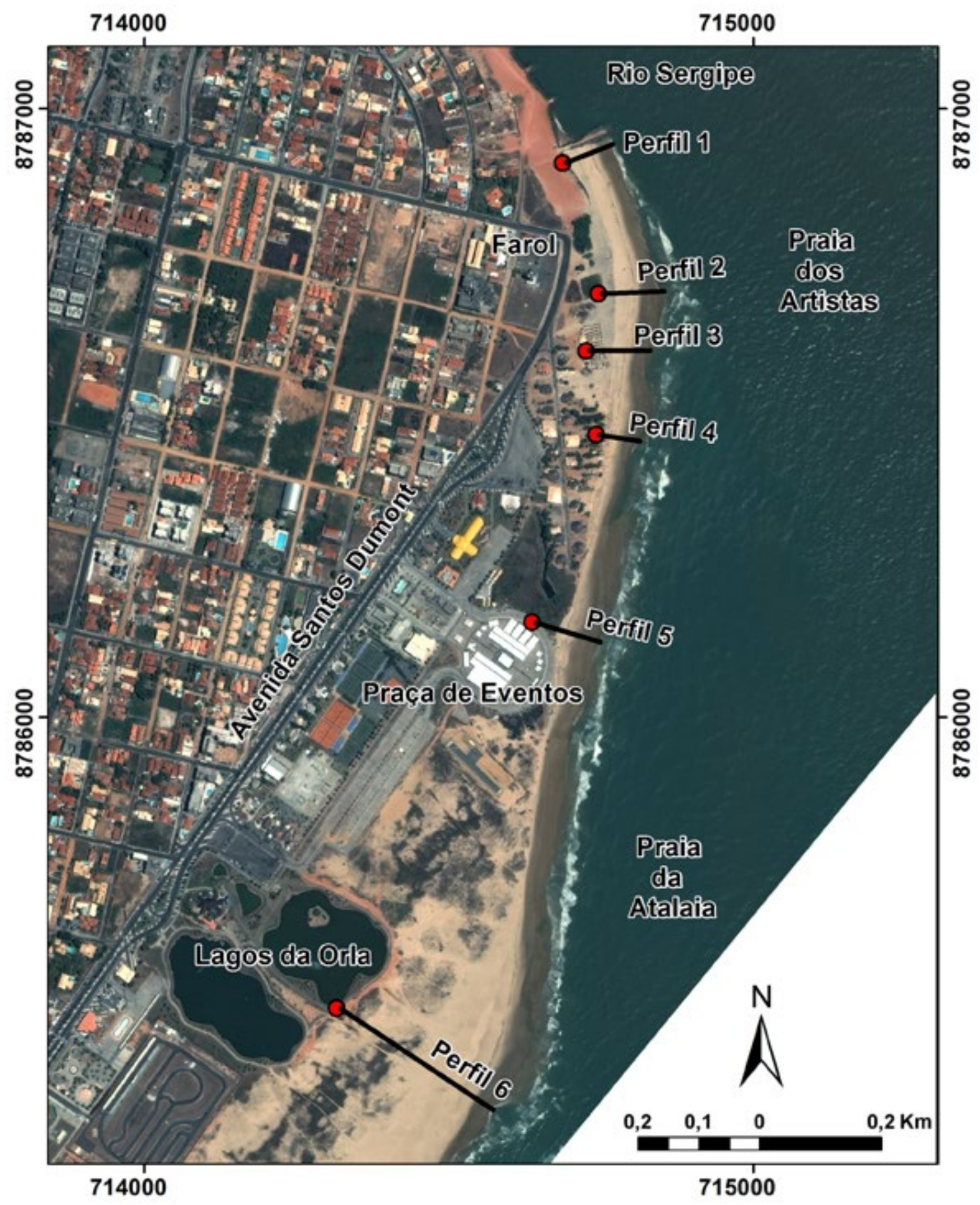

\section{Legenda}

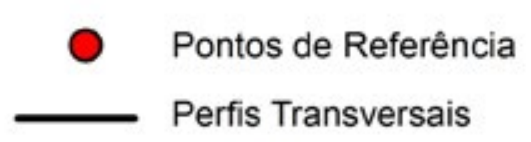

Sistema de Coordenadas Projetadas Universal Transversa de Mercator Datum South America SIRGAS 2000

Imagem QuickBird 2008 (EMURB - Aracaju - SE)

Figura 3. Localização dos 6 perfis transversais realizados nas praias contíguas à margem direita da desembocadura do rio Sergipe.

Figure 3. Location of the 6 transversal profiles carried out on the adjacent beaches on the right margin of the Sergipe's river mouth. 

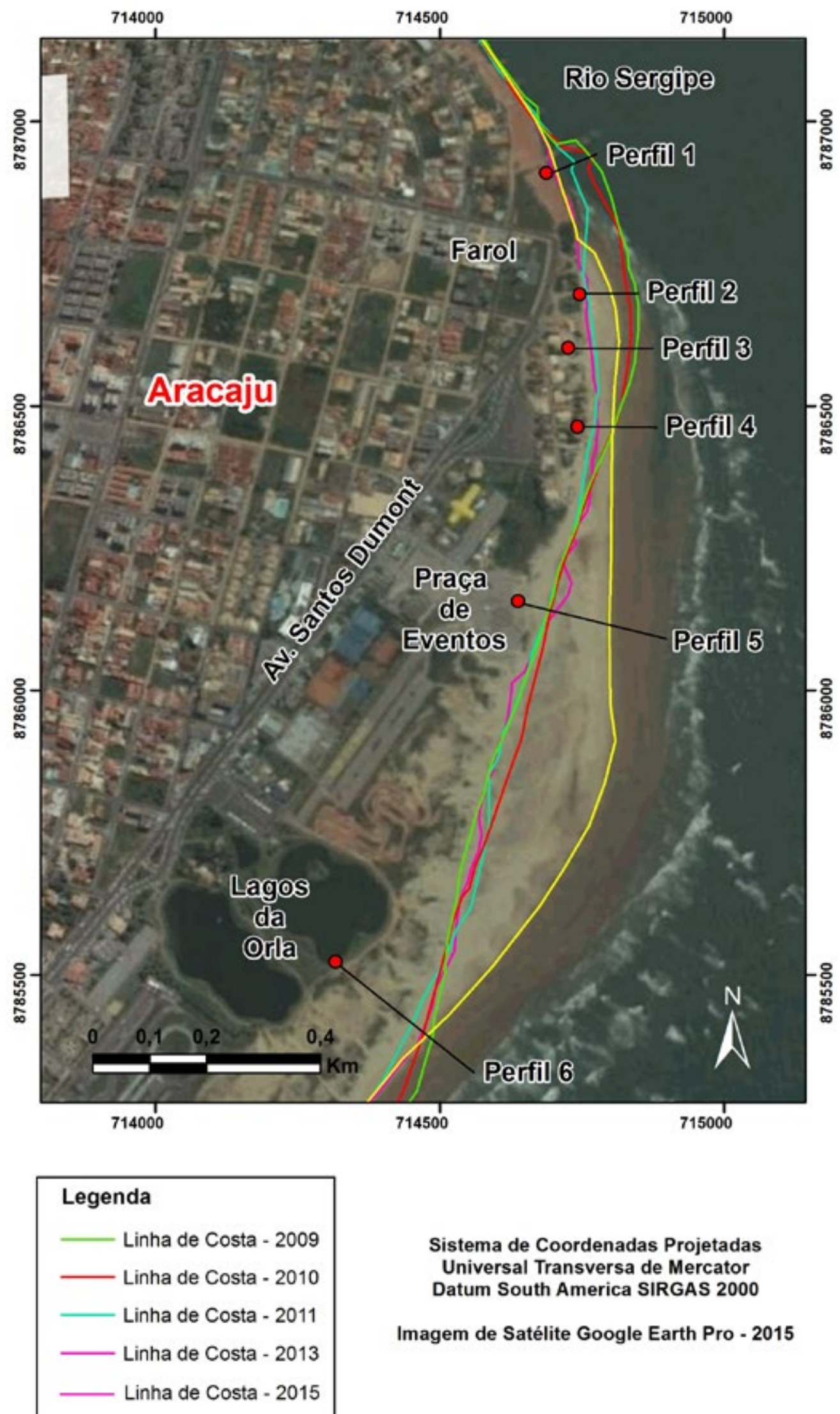

\section{Sistema de Coordenadas Projetadas \\ Universal Transversa de Mercator \\ Datum South America SIRGAS 2000}

Imagem de Satélite Google Earth Pro - 2015

Figura 4. Comportamento da linha de costa nas praias contíguas à desembocadura do rio Sergipe, Aracaju, Sergipe no período de 2009 a 2015. Fonte: Imagem de satélite do Google Earth Pro do ano de 2015.

Figure 4. High tide shoreline behavior on beaches adjacent to Sergipe's river mouth, Aracaju, Sergipe from 2009 to 2015. Image source: Satellite image from Google Earth Pro in 2015. 
Tabela 1. Comparação entre os dados de taxa de variação da linha de costa obtidos a partir de imagens de satélite e perfis de praia.

Table 1. Comparison between the shoreline rate-of-change obtained from satellite images and beach profiles.

\begin{tabular}{lcc}
\hline & $\begin{array}{c}\text { Imagens de Satélite } \\
\text { (2009-2015) }\end{array}$ & $\begin{array}{c}\text { Perfis de Praia } \\
(\mathbf{2 0 0 8 - 2 0 1 5 )}\end{array}$ \\
\hline Perfil 1 & $-13 \mathrm{~m} / \mathrm{ano}$ & $-11 \mathrm{~m} / \mathrm{ano}^{*}$ \\
Perfil 2 & $-8 \mathrm{~m} / \mathrm{ano}$ & $-5 \mathrm{~m} / \mathrm{ano}^{* *}$ \\
Perfil 3 & $-6 \mathrm{~m} / \mathrm{ano}$ & $-0,5 \mathrm{~m} / \mathrm{ano}$ \\
Perfil 4 & 0 & $+1 \mathrm{~m} / \mathrm{ano}$ \\
Perfil 5 & $+18 \mathrm{~m} / \mathrm{ano}$ & $+15 \mathrm{~m} / \mathrm{ano}$ \\
Perfil 6 & $-3 \mathrm{~m} / \mathrm{ano}$ & $-12 \mathrm{~m} / \mathrm{ano}$ \\
\hline Período de análise: 2008 a 2013* e $2008-2014^{* *}$. Faixas \\
de proteção não foram calculadas & $* * *$, pois a taxa de
\end{tabular}

3.2 Taxa de variação da linha de costa obtida pela análise de perfis de praia para o período de 20082015

A taxa de variação da linha de costa extraída de dados de perfis de praia, para o período de 2008 a 2015, foi negativa nos perfis 1, 2, 3 e 6, e positiva nos perfis 4 e 5 (Tab. 1, fig. 5). A linha de costa variou significativamente em todos os perfis, conforme mostra a figura 5 , na qual os dados intermediários estão dispersos em relação à reta que une os pontos extremos. A figura 6 ilustra as modificações ocorridas na linha de costa nos perfis em diferentes datas.

\subsection{Comparação e análise das taxas de variação da} linha de costa

A comparação dos valores de taxa de variação da linha de costa a partir dos perfis de praia e das imagens de satélite mostrou uma sutil diferença do resultado obtido pelos dois métodos (Tab. 1).

De acordo com Smith \& Zarillo (1990), há maior precisão dos dados extraídos dos perfis de praia. No entanto, a sobreposição das linhas de costa multitemporais a partir das imagens de satélite permitiu uma melhor visualização espacial, pois foram mostradas de forma contínua, diferentemente dos perfis que apresentaram apenas dados pontuais.

A taxa de variação da linha de costa encontrada em alguns dos perfis de praias foi um pouco alta comparada com outras localidades. A literatura, em geral, mostra taxas inferiores a $10 \mathrm{~m} / \mathrm{ano}$, tanto para recuo quanto avanço (Dolan et al., 1978; Smith \& Zarillo, 1990; Dolan et al., 1991; Crowell et al., 1991; Forbes \& Liverman, 1996; Galgano Jr., 2008; Mazzer \& Dillenburg, 2009; Absalonsen \& Dean, 2011). Os trabalhos de Souza \& Luna (2010), Genz et al. (2007) e Macedo et al. (2012) mostram taxas de variação da linha de costa superiores a 10 m/ano. Forbes \& Liverman (1996) afirmam que taxas mais altas que $10 \mathrm{~m} /$ ano são encontradas em costas baixas como na Nigéria e na China. Adicionalmente, altos valores de taxa são esperados em áreas com elevada variabilidade morfológica, como as regiões próximas às desembocaduras fluviais, conforme mostrado por Chaaban et al. (2012). Isso justifica, portanto, as elevadas taxas encontradas para a área investigada.

\subsection{Faixas de Proteção Costeira}

Os valores de faixa de proteção obtidos para construções leves variaram de 0 a $360 \mathrm{~m}$ e para construções pesadas, de 20 a 730 m (Tab. 2). No entanto, foi sugerido os maiores valores para a área investigada, ou seja, a largura de $360 \mathrm{~m}$ para construções leves (Fig. 7A) e de 730 m para construções pesadas (Fig. 7B). Esses valores estão acima daqueles estipulados no Decreto de Lei 9.760, de 05.09.1946, de 33 m (Freitas, 2011), em outros países e no projeto Orla (Muehe, 2004, p. 19). A área de estudo encontra-se situada na margem de uma desembocadura fluvial estabilizada com obras de contenção. Entretanto, apesar das obras, essa região apresentou alternância de processos erosivos e deposicionais nas últimas décadas, conforme explicitado por Bittencourt et al. (2006) e Rodrigues et al. (2015a). Adicionalmente, na desembocadura do rio Sergipe são formados bancos arenosos, como deltas de maré vazante (Rodrigues et al., $2015 b)$ que, por vezes, são levados até a praia pela ação das ondas soldando-se à praia. Por outro lado, à medida que esses bancos são empurrados em direção à praia, deslocam o canal principal do rio, que se aproxima da praia, causando erosão. Esse fato, pôde ser observado através das imagens de satélite multitemporais. Devido à corrente longitudinal predominante de NE-SW, esses bancos são carregados longitudinalmente à praia no sentido SW como um processo de migração praial. Sendo 

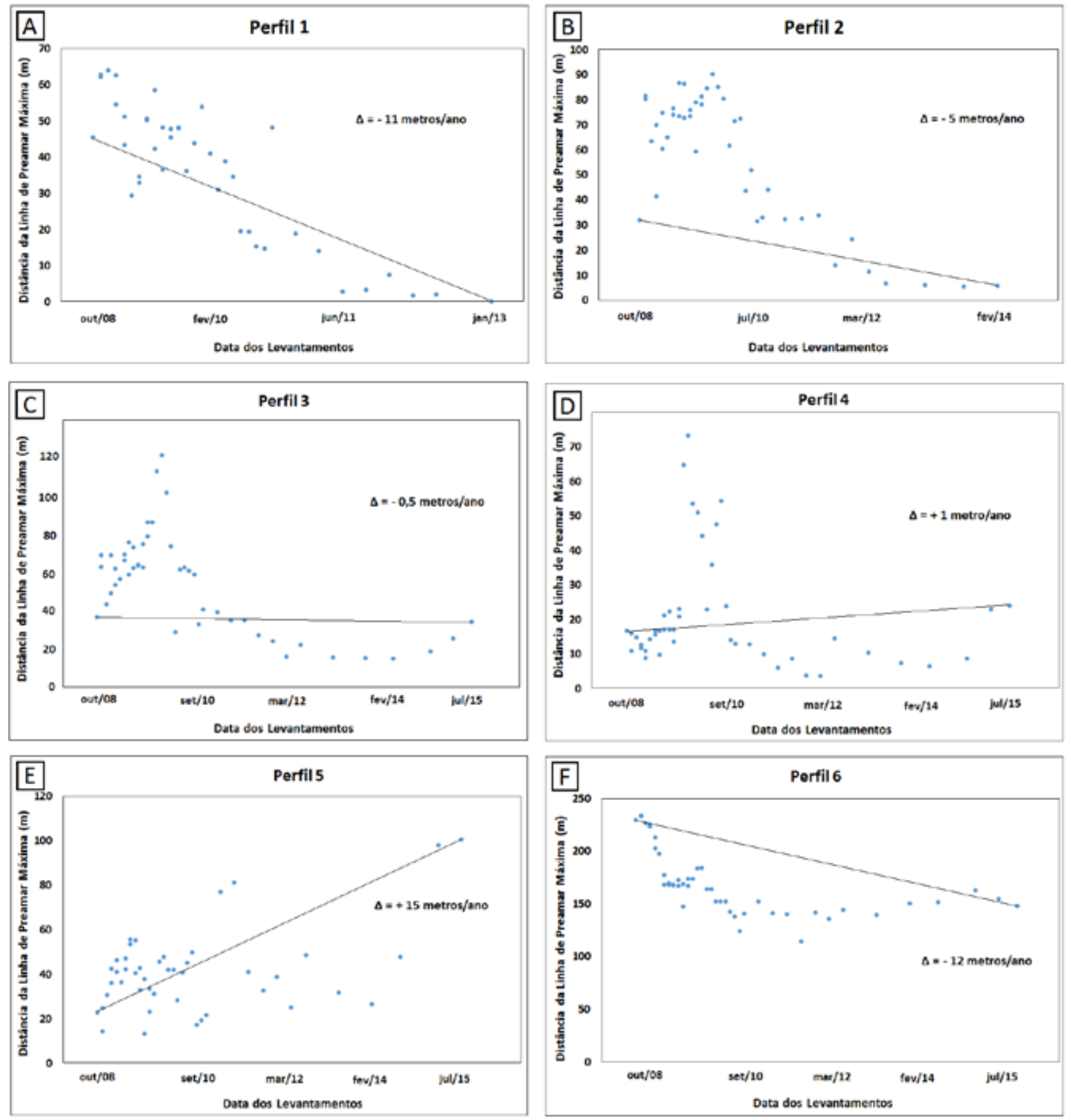

Figura 5. Série temporal de mudanças na configuração da linha de costa nos seis perfis transversais às praias dos Artistas e da Atalaia, Aracaju, Sergipe. A) Taxa de variação da linha de costa negativa no perfil 1; B) Taxa de variação da linha de costa negativa no perfil 2; C) Taxa de variação da linha de costa negativa no perfil 3; D) Taxa de variação da linha de costa positiva no perfil 4; E) Taxa de variação positiva no perfil 5; F) Taxa de variação da linha de costa negativa no perfil 6. A reta conecta os pontos iniciais e finais utilizados no cálculo da taxa de variação da linha de costa pelo método EPR descrito por Dolan et al. (1991). Os demais pontos representam as medições obtidas nos períodos intermediários e foram plotados apenas para mostrar a grande variabilidade dessa linha nos perfis no decorrer do tempo.

Figure 5. Temporal series of shoreline changes on the six profiles at the Artistas and Atalaia beaches, Aracaju, Sergipe. A) Negative shoreline rate-of-change on profile 1;B)Negative shoreline rate-of-change on profile 2; C)Negative shoreline rate-of-change on profile 3; D)Positive shoreline rate-of-change on profile 4; E)Positive shoreline rate-of-change on profile 5; F)Negative shoreline rate-of-change on profile 6. The line connects the initial and final points utilized on the calculation of the shoreline rate-of-change using the EPR method described by Dolan et al. (1991). The other points represent the measurements obtained by the intermediate dates and were only plotted to show the great variability of this line on profiles throughout time. 

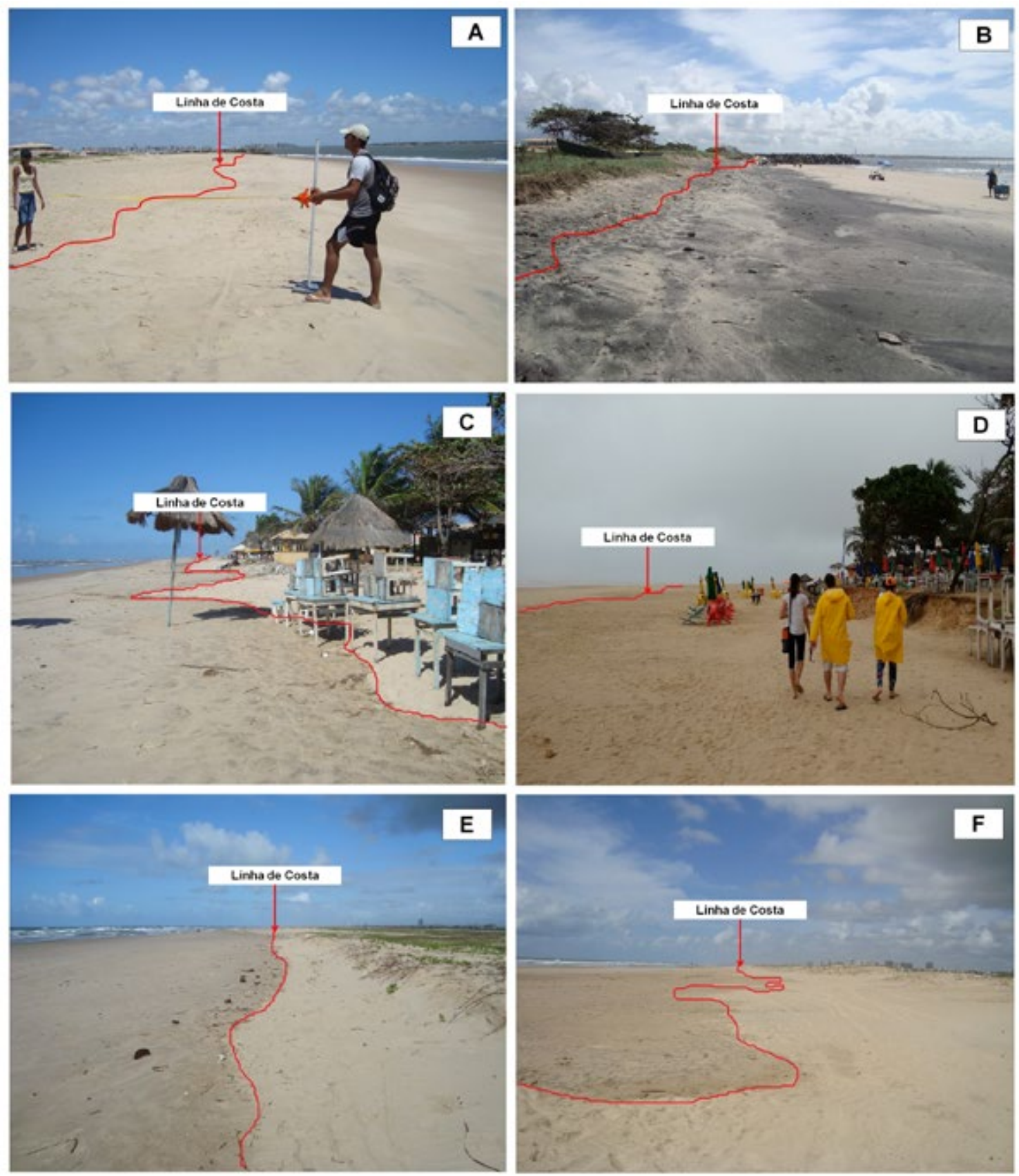

Figura 6. Sequência de fotografias de campo ilustrando a linha de costa (preamar máxima) obtida nos perfis de praia. A) Linha de costa no perfil 2 em 2009 estava afastada da linha de vegetação; B) Linha de costa no perfil 2 em 2012 estava mais próxima da linha de vegetação; C) Linha de costa no perfil 4 em 2009 estava próxima das barracas de praia; D) Linha de costa no perfil 4 em 2015 estava mais afastada das barracas de praia; E) Linha de costa no perfil 6 em 2009 estava próxima da linha de vegetação; F) Linha de costa no perfil 6 em 2016 estava mais afastada da linha de vegetação.

Figure 6. A sequence of field photographs illustrating the shoreline (high tide shoreline) obtained from beach profiles. A) Shoreline in profile 2 in 2009 was away from the vegetation line; B) Shoreline in profile 2 in 2012 was closest to the vegetation line; C) Shoreline in profile 4 in 2009 was near the beach tents; D) Shoreline in profile 4 in 2015 was furthest from beach huts; E) Shoreline in profile 6 in 2009 was near to the vegetation line; F) Shoreline in profile 6 in 2016 was further from the vegetation line. 
Tabela 2. Faixas de proteção para cada perfil de praia considerando o período de 2008 a 2015.

Table 2. Setback lines for each beach profile considering the period from 2008 to 2015.

\begin{tabular}{lcc}
\hline & Construções Leves & Construções Pesadas \\
\hline Perfil 1* & $320 \mathrm{~m}$ & $640 \mathrm{~m}$ \\
Perfil 2** & $148 \mathrm{~m}$ & $300 \mathrm{~m}$ \\
Perfil 3 & $10 \mathrm{~m}$ & $20 \mathrm{~m}$ \\
Perfil 4*** & - & - \\
Perfil 5*** & - & - \\
Perfil 6 & $360 \mathrm{~m}$ & $730 \mathrm{~m}$ \\
\hline Período de análise: 2008 a $2013^{*}$ e 2008-2014**. Faixas de proteção \\
não foram calculadas ***, pois a taxa de variação da linha de costa \\
foi positiva.
\end{tabular}
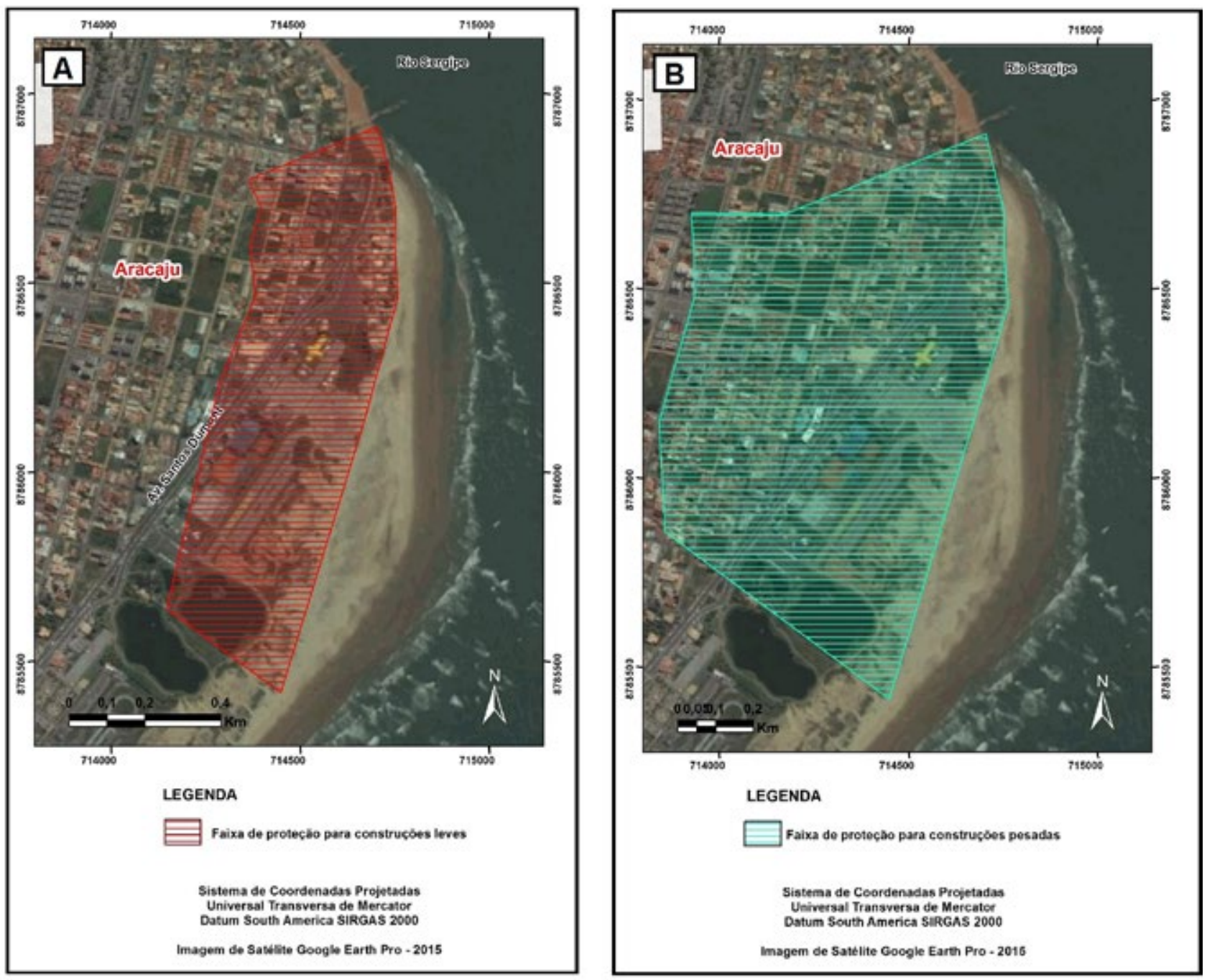

Figura 7. Imagem de satélite do Google Earth Pro de 2015 ilustrando a demarcação de faixas de proteção propostas nesse trabalho. A) Faixa de proteção para construções leves; B) Faixa de proteção para construções pesadas. Observe que as faixas propostas recobrem áreas ocupadas. Nesse caso, recomenda-se apenas evitar novas construções nessas aéreas.

Figure 7. Satellite image of Google Earth Pro of 2015 showing the limitation of the setback proposed at this work. A) Setback for soft constructions; B) Setback for hard constructions. Note that these setbacks cover occupied areas. In that case, it is only recommended not to build more in these areas. 
assim, por se tratar de praias de desembocadura fluvial, a linha de costa da área estudada apresenta alta variabilidade (Bittencourt et al., 2006) e, por isso, necessita de faixas de proteção mais largas.

As faixas de proteção são estabelecidas como medida preventiva à construção de estruturas antrópicas em regiões sob erosão costeira (Muehe, 2004). No entanto, em áreas já ocupadas, como na área investigada, podem ocorrer dificuldades de implementação de faixas de proteção superiores a $300 \mathrm{~m}$ (Fig. 7A e Fig. 7B). Porém, a faixa de proteção deve ser levada em consideração, principalmente, na instalação de novas estruturas antrópicas.

Adicionalmente, segundo Muehe (2004) é importante o estabelecimento de faixas de proteção nas proximidades de rios que não possuam estruturas de contenção à erosão. 0 rio Sergipe apresenta tais estruturas, porém, é possível notar que essas estruturas não estão recebendo a manutenção necessária (Fig. 8). Além disso, essas medidas de correção apenas transferiram o problema para sotamar, conforme verificado na área investigada, erodindo a linha de costa nos demais pontos analisados onde não existiam obras de contenção. A migração de processo erosivo nessas praias foi observada em imagens de satélite por Rodrigues et al. (2015a) e em dados de campo por Jesus et al. (2012).

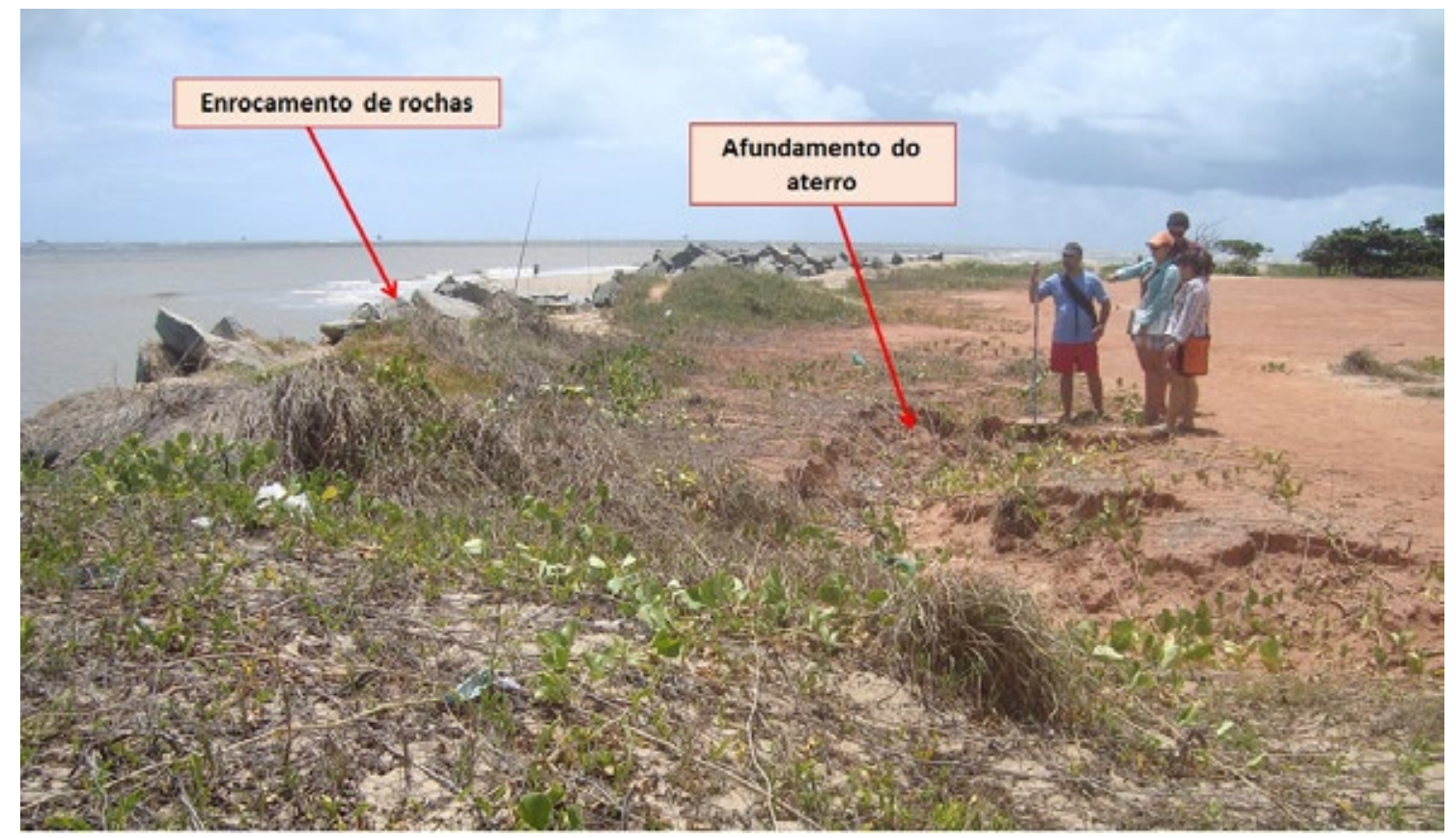

Figura 8. Aterro com indícios de afundamento na retaguarda do enrocamento de rochas presente no perfil de praia 1 em 2014. Figure 8. Landfill with evidence of sinking behind rip rap present on beach profile 1 in 2014.

\section{Conclusões}

A linha de costa contígua à margem direita da desembocadura do rio Sergipe (praias dos Artistas e da Atalaia), em todos os perfis, variou significativamente no período de 2008 a 2015, não seguindo uma tendência linear de avanço ou recuo.

As taxas de recuo apresentaram valores na ordem de poucos metros a poucas dezenas de metros ( $<20 \mathrm{~m} / \mathrm{ano}$ ) tanto para avanço quanto recuo e, permitiu sugerir o estabelecimento de duas fai- xas de proteção: de $360 \mathrm{~m}$ para construções leves e de $730 \mathrm{~m}$ para construções pesadas.

A comparação dos valores de taxa de variação da linha de costa a partir dos perfis de praia e das imagens de satélite mostrou uma sutil diferença do resultado obtido pelos dois métodos. No entanto, deve-se levar em consideração que os dados extraídos a partir dos perfis de praia são mais precisos, pois são coletados in situ. Por outro lado, as imagens de satélite mostraram as variações espaciais da linha de costa, enquanto que os perfis 
ilustraram apenas as variações pontuais.

As medidas corretivas, tais com as estruturas de contenção instaladas na área estudada, apenas transferiram o problema de erosão para as áreas situadas à sotamar. Conforme verificado nesse trabalho, o problema de erosão da área de estudo não foi solucionado definitivamente devido à reincidência de eventos erosivos. Dessa forma, medidas preventivas, a exemplo da utilização de faixas de proteção recomendadas nesse trabalho devem ser incentivadas.

Em áreas já ocupadas, como na área investigada, essas faixas devem ser consideradas na instalação de novos empreendimentos, a fim de se evitar danos sócio-econômicos caso ocorram futuros eventos erosivos. Entretanto, cabe salientar que as faixas de proteção devem ser avaliadas periodicamente podendo ser alteradas a partir da aquisição de novos dados de variação da linha de costa, uma vez que essa linha é bastante dinâmica e sensível às mudanças climáticas.

Esse trabalho forneceu uma documentação das mudanças da linha de costa em curto prazo. Para fins de planejamento costeiro é importante também se considerar a documentação das mudanças em outras escalas de tempo (médio e longo prazo). A continuação do monitoramento dessas praias é necessária, pois a tendência atual não deverá se manter por muito tempo, conforme mencionado anteriormente, por se tratar de uma área bastante instável.

Adicionalmente, as praias e as linhas de costa são ambientes sensíveis aos impactos das mudanças climáticas, a exemplo da elevação do nível médio do mar, das alterações no ângulo de aproximação de ondas e/ou da intensificação das tempestades. Entretanto, aparentemente, os órgãos públicos não consideram a alta variabilidade morfológica da linha de costa, nem as previsões futuras decorrentes das mudanças climáticas globais. Dessa forma, esse trabalho pode auxiliar no planejamento urbano e ambiental da área estudada.

Agradecimentos. 0 presente trabalho foi realizado como apoio da Coordenação de Aperfeiçoamento de Pessoal de Nível Superior - Brasil (CAPES) Código de Financiamento 001. Os autores também agradecem ao(à): CNPq pelo auxílio financeiro a projeto de pesquisa, INCT-Ambientes Tropicais Marinhos, EMURB-Aracaju pela disponibilização de imagem de satélite QuickBird, e a Msc. Joanna Cecília da Silva Santos e ao Dr. Carlos Dinges Marques de Sá pela revisão do texto em inglês.

\section{Referências bibliográficas}

Absalonsen, L. \& Dean R.G. 2011. Characteristics of the shoreline change along Florida sandy beaches with an example for Palm Beach County. Journal of Coastal Research, 27(6A): 16-26.

ANA. Agência Nacional de Águas. 2000. Plano diretor de Desenvolvimento de Recursos Hídricos. Disponível em: http://hidroweb.ana.gov.br/ cd1/parte1.htm. Acesso em 24 jul. 2017.

Andrade, A.C.S., Santos, G.C., Oliveira, L.S., Siqueira, J.E.O., Rodrigues, T.K., Lavenère-Wanderley, A.A.O. \& Nascimento, F.M. 2010. Recuperação natural do ambiente praial: o exemplo da Orlinha da Coroa do Meio - Aracaju - SE. In: CONGRESSO BRASILEIRO DE OCEANOGRAFIA, IV, 2010. Rio Grande. Anais do CBO'2010, p. 864 $-866$.

Bird, E. 2008. Coastal geomorphology: an introduction. New York: John Wiley \& Sons, 436 p.

Bittencourt, A.C.S.P., Martin, L., Dominguez, J.M.L. \& Ferreira, Y.A. 1983. Evolução paleogeográfica quaternária da costa do Estado de Sergipe e da costa sul do estado de Alagoas. Revista Brasileira de Geociências, 13(2): 93-97.

Bittencourt, A.C.S.P., Dominguez, J.M.L. \& Oliveira, M.B. 2006. Sergipe. In: Muehe, D. (Org.) Erosão e progradação do litoral brasileiro, Brasília, Ministério do Meio Ambiente. p.213-218.

Boak, E.H. \& Turner, I.L. 2005. Shoreline definition and detection: a review. Journal of Coastal Research, 21(4): 688-703.

Chaaban, F., Darwishe, H., Battiau-Queney, I., Louche, B., Masson, E., El Khattabi, J. \& Carlier, E. 2012. Using ArcGIS® Modelbuilder and Aerial Photographs to Measure Coastline Retreat and Advance: North of France. Journal of Coastal Research, 28(6):1567- 1579.

Cicin-Sain, B. \& Knecht, R.W.1998. Integrated coastal and ocean management: Concepts and practices. Washington: Island Press, 517p.

Crowell, M., Leatherman, S.P. \& Buckley, M.E. 1991. 
Historical shoreline change: error analysis and mapping accuracy. Journal of Coastal Research, 7(3): 839-852.

Crowell, M., Leatherman, S.P. \& Buckley, M.K. 1993.

Shoreline change rate analysis: long term versus short-term data. Shore and Beach, 61(2):1320

DEA\&DP. Department of Environmental Affairs \& Development Planning. 2010. Development of a Methodology for Defining and Adopting Coastal Development Setback Lines - vol. 1. WSP Africa Coastal Engineers (Pty), 81p.

DHN. Diretoria de Hidrografia e Navegação. 2017. Tábuas de Maré. Marinha do Brasil. Disponível em: http://www.dhn.br. Acesso em: 24 jul. 2017.

Dolan, R., Hayden, B. \& Heywood, J. 1978. A new photogrammetric method for determining shoreline erosion. Coastal Engineering, 2: 21-39.

Dolan, R., Fenster, M.S. \& Holme, S.J. 1991. Temporal analysis of shoreline recession and accretion. Journal of Coastal Research, 7(3): 723-744.

Douglas, B.C. \& Crowell, M. 2000. Long-term shoreline position prediction and error propagation. Journal of Coastal Research, 16(1): 145-152.

Emery, K.O. 1961. A simple method of measuring beach profiles. Limnology and Oceanography, 6: 90-93.

Esteves, L.S., Dillenburg, S.R. \& Toldo Jr., E.E. 2006. Alongshore patterns of shoreline movements in southern Brasil. Journal of Coastal Research, 39: 215-219.

Esteves, L.S., William, J.J., Nock, A. \& Lymbery, G. 2009. Quantifying shoreline changes along the Sefton coast (UK) and the implications for research-informed coastal management. Journal of Coastal Research, S156: 602-606.

Ferreira, O., Garcia, T., Matias, A., Taborda, R. \& Dias, J.A. 2006. An integrated method for the determination of setback lines for coastal erosion hazards on sandy shores. Continental Shelf Research, 26(1): 1030-1044.

Forbes, D.L. \& Liverman, D.G.E. 1996. Geological indicators in coastal zone. In: Berger, A.N. \& Iams, W.J. (Eds.), Geoindicators: Assessing rapid environmental changes in Earth systems. Rotterdam: A.A. Balkema, p. 173-192.

Foster, E.R. \& Savage, R.J. 1989. Methods of histori- cal shoreline analysis. In: Coastal Zone '89, Proceedings of the Sixth Symposium on Coastal and Ocean Management. New York: ASCE, p. 44204433.

Freitas, M.A.P. 2011. Zona Costeira: Aspectos Jurídicos. Curitiba: Editora Juruá. 232p.

Galgano Jr., F.A. 2008. Shoreline Behavior Along The Atlantic Coast Of Delaware. Middle States Geographer, 41:74 -81.

Genz, A.S., Fletcher, C.H., Dunn, R.A., Frazer, N. \& Rooney, J.J. 2007. The Predictive Accuracy of Shoreline Change Rate Methods and Alongshore Beach Variation on Maui, Hawaii. Journal of Coastal Research, 23(1): 87-105.

Honeycutt, M.G., Crowell, M. \& Douglas, B.C. 2001. Shoreline-Position Forecasting: Impact of Storms, Rate-Calculation Methodologies, and Temporal Scales. Journal of Coastal Research, 17(3): 721-730.

INMET. Instituto Nacional de Meteorologia. 2011. Temperaturas médias mensais para Aracaju no período de 1961 a 1990. Disponível em: http:// www.inmet.gov.br/. Acesso em 24 jul. 2017.

IPCC. Intergovernmental Panel on Climate Change. 2007. Climate change 2007: the physical science basis, Contribution of Working Group I to the Fourth Assessment Report of the Intergovernmental Panel. In: Solomon, S, Qin, D, Manning, D, Chen, Z, Marquis, M, Averyt, K.B, Tignor, M, Miller, H.L. Climate Change. Cambridge University Press. p. 287-350.

Jesus, L.V., Rodrigues, T.K., Nascimento, F.M., Souza, C.S.M, Dalan, C.A., Rosa, L.R.J., Dantas, N.V. \& Andrade, A.C.S. 2012. Migração do processo erosivo nas praias da Orlinha da Coroa do Meio - Aracaju - SE. In: CONGRESSO BRASILEIRO DE GEOLOGIA, 46., 2012, SANTOS/SP, Anais do $46^{\circ}$ $C B G$, SBG.

Jesus, L.V., Paixão, T.F.S., Feitosa, R.T., Santos, J.P.S. \& Andrade, A.C.S. 2014. Balanço Sedimentar e Mudanças na Linha de Costa das Praias dos Artistas e Atalaia Velha - Aracaju/SE no período de 2008 a 2014. In: CONGRESSO BRASILEIRO DE GEOLOGIA, 47., 2014, Salvador/BA, Anais do 47은, $C B G$, p. 79.

Leatherman, S. 2003. Shoreline change mapping and management along the U.S. East Coast. Journal of Coastal Research, SI(38):5- 3. 
Macedo, R.J.A., Manso, V.A.V., Pereira, N.S. \& França, L.G. 2012. Transporte de sedimentos e variação da linha de costa em curto prazo na praia de Maracaípe (PE), Brasil. Revista da Gestão Costeira Integrada, 12(3): 343-355.

Mazzer, A.M. \& Dillenburg, S. 2009. Variações temporais da linha de costa em praias arenosas dominadas por ondas do sudoeste da Ilha de Santa Catarina (Florianópolis, SC, Brasil). Pesquisas em Geociências, 36(1): 117-135.

Moore, L.J. 2000. Shoreline mapping techniques. Journal of Coastal Research, 16(1): 111-114.

Morton, R.A. 1996. Geoindicators of coastal wetlands and shorelines. In: Berger, A.R. \& Iams, W.J. (Eds.). Assessing Rapid Environmental Geoindicators Changes in Earth Systems. Rotterdam: A. A. Balkema, p. 207-230.

MTur. Ministério do Turismo. 2013. Turismo investe em orla de Aracaju. Disponível em: http:// www.turismo.gov.br/ultimas-noticias/1992turismo-investe-em-orla-de-aracaju.html. Acesso em: 24 jul. 2017.

Muehe, D. 2001. Critérios morfodinâmicos para o estabelecimento de limites da Orla Costeira para fins de gerenciamento. Revista Brasileira de Geomorfologia, 2(1): 35-44.

Muehe, D. 2004. Definição de limites e tipologias da orla sob os aspectos morfodinâmico e evolutivo. In: Muehe, D. (Eds.) Projeto Orla - Subsídios para um Projeto de Gestão. Brasília: MMA e MPO. p: 11-30.

Oliveira, M.B. 2003. Caracterização integrada da linha de costa do Estado de Sergipe - Brasil. Bahia, 102p. Dissertação de Mestrado, Programa de Pós-graduação em Geologia, Instituto de Geociências, Universidade Federal da Bahia.

Oliveira, L.S., Santos, G.C., Siqueira, J.E.O., Nascimento, F.M. \& Andrade, A.C.S. 2010. Variabilidade sazonal dos perfis de praia na Atalaia Velha - Aracaju - SE. In: CONGRESSO BRASILEIRO DE OCEANOGRAFIA, IV, 2010. Rio Grande. Anais do CBO'2010, p. 3326-3328.

Pianca, C., Mazzini, P.L. \& Siegle E. 2010. Brazilian offshore wave climate based on NWW3 reanalysis. Brazilian Journal of Oceanography, 58(1): 53-70.

Rodrigues, T.K. 2008. Análise das Mudanças da Linha de Costa das Principais Desembocaduras do Estado de Sergipe, com Ênfase no rio Sergipe. 79p. Dissertação de Mestrado. Programa de Pós-graduação em Geologia, Instituto de Geociências, Universidade Federal da Bahia.

Rodrigues, T.K. 2014. Impactos das Mudanças Climáticas na Zona Costeira do município de Aracaju-SE: Estudo de Caso Utilizando o SMC (Sistema de Modelagem Costeira). 121p. Tese de Doutorado. Programa de Pós-graduação em Geologia, Instituto de Geociências, Universidade Federal da Bahia.

Rodrigues, T.K., Pereira, D.A.S., Feitosa, E.S.S., Jesus, L.V., Silva, M.G., Andrade, A.C.S., Dominguez, J.M.L. \& Lavenere-Wanderley, A.A.O. 2015a. Comportamento da linha de costa e ocupação humana na Atalaia Velha e no Mosqueiro, Aracaju, SE. Scientia Plena, 11: 1-6.

Rodrigues, T.K., Jesus L.V., Silva, M.G., Pereira, D.A.S., Feitosa, E.S.S., Andrade, A.C.S., Dominguez, J.M.L. \& Lavenere-Wanderley, A.A.O. 2015b. Deltas de Maré Vazante e Erosão Costeira na Atalaia Velha e no Mosqueiro, Aracaju (SE) no período de 1965 a 2008. Scientia Plena, 11: 1-7.

Silva, M.G. 2014. Geoindicadores de erosão e acumulação das praias do município de Aracaju Sergipe. Sergipe, 71p. Dissertação de Mestrado, Programa de Pós-Graduação em Geociências e Análise de Bacias, PGAB, Universidade Federal de Sergipe.

Smith, G. \& Zarillo, G. 1990. Calculating long-term shoreline recession rates using aerial photographic and beach profiling techniques. Journal of Coastal Research, 18(3): 502-513.

Souza, C.R.G. \& Luna, G.C. 2010. Variação da linha de costa e balanço sedimentar de longo período em praias sob risco muito alto de erosão do município de Caraguatatuba (Litoral Norte de São Paulo, Brasil). Revista da Gestão Costeira Integrada, 10(2): 179-199.

SRH. Superintendência de Recursos Hídricos. 2011. Atlas Digital sobre Recursos Hídricos de Sergipe, Cd-rom.

Stive, M.J.F., Aarninkhof, S.G.J., Hamm, L., Hanson, H., Larson, M., Wijnberg, K.M., Nicholls, R.J. \& Capobianco, M. 2002. Variability of shore and shoreline evolution. Coastal Engineering, 47: 211-235.

Terich, T.A. 1987. Living with the shore of $\mathrm{Pu}$ - 
get Sound and Georgia Strait. Duke University Press, Durham, National Audubon Society, 165 p.

Vieira, M. 2008. Maré alta destrói mais áreas da praça de eventos da orla: calçada e estacionamentos são os mais atingidos pela ressaca do mar. Jornal da Cidade, Aracaju, 25 jan. Caderno B. p. 2.

Wanderley, L.L. 2006. Paisagem na janela: esse nosso inconstante rio Sergipe e a evolução de sua Foz. In: Alves, J.P.H. (Org.). Rio Sergipe: importância, vulnerabilidade e preservação. Aracaju-SE: Ós Editora. p: 167-194. 